\title{
THE ZEBRAFISH ANIMAL MODEL (Danio rerio) USED FOR DIFFERENT THERAPEUTIC APPROACHES FOR THE SUPPRESSION OF EPILEPTIC CRISIS: A SYSTEMATIC REVIEW
}

\author{
O MODELO ANIMAL DO ZEBRAFISH (DANIO RERIO) USADO PARA DIFERENTES \\ ABORDAGENS TERAPÊUTICAS PARA A SUPRESSÃO DA CRISE EPILÉPTICA: UMA \\ REVISÃO SISTEMÁTICA
}

\author{
Islane Cristina Martins ${ }^{1}$ \\ Pabyton Gonçalves Cadena ${ }^{2}$
}

\begin{abstract}
Epilepsy represents one of the most common neurological diseases, affecting about 70 million people worldwide. Recent advances in genetic research have discovered a wide spectrum of genes involved in various forms of epilepsy, their cause may be due to inflammation, neuronal trauma or brain malformations, highlighting the heterogeneous nature of this disorder. In addition, unfortunately, older epileptic drugs have many side effects, with cognitive impairment being the main side effect that affects the daily lives of people with epilepsy. Appropriate animal models are essential to investigate the pathological mechanisms triggered by genetic mutations involved in epilepsy and to develop specific and targeted therapies. The models of zebrafish diseases (Danio rerio) are relevant to the pathophysiology of human diseases. In recent years, zebrafish has emerged as a valuable vertebrate organism for modeling epilepsies, using genetic manipulation or exposure to know epileptogenic drugs, such as pentylenetetrazole (PTZ), to identify new antiepileptic therapies. The aim of the present study was to conduct a systematic review of the literature in order to understand how zebrafish has been used for the study of epilepsy. For this purpose, a literature search was made in the Medline, Lilacs, Science, Citation Index, SciELO, PUBMED, Google Scholar, CAPES and BVS Bireme databases. The keywords used were: "Suppression of the epileptic crisis", "Animal Model", "Zebrafish" in the databases. As a result, it was possible to observe 16 articles included after the qualitative synthesis, of these, $44 \%$ of the articles analyzed a certain drug in the treatment of epilepsy, 30\% dealt with the induction of epilepsy to study the pathways involved in this disease, $22 \%$ carried out studies strictly involved to Dravet's Syndrome. In conclusion, it can be said that developing an animal model for brain disorders, particularly epilepsy, is very difficult due to the complexity of the disease. Most of the preclinical research on epilepsy has focused on rodents. However, recent research points to zebrafish as an excellent target for laboratory analysis, as it has a great similarity to mammals and is highly advantageous with its unique properties, such as external fertilization, small size, as well as optical clarity of embryos. The central role of receptors in epilepsy demonstrates the potential usefulness of targets for controlling seizures in these animal models.
\end{abstract}

Keywords: Animal Model. Epilepsy. Suppression epileptic crisis. Zebrafish.

'Biomédica pela Universidade Federal de Pernambuco-PE, mestre em Neurociências pelo Programa de PósGraduação em Neuropsiquiatria e Ciências do Comportamento -UFPE e doutoranda pelo PPGBAS LIKAUFPE. Professional and Self Coach-IBC.E-mail: islanemartins@gmail.com.

2 Doutor em Ciências Biológicas. Pós-Doutorado na IUPUI (Indiana University Purdue University Indianapolis), Estados Unidos. Laboratório de Ecofisiologia e Comportamento Animal (LECA), Universidade Federal Rural de Pernambuco. 
RESUMO: A epilepsia representa uma das doenças neurológicas mais comuns, afetando cerca de 70 milhões de pessoas em todo o mundo. Avanços recentes na pesquisa genética descobriram um grande espectro de genes implicados em várias formas de epilepsia, sua causa pode ser por inflamação, neurotrauma ou malformações cerebrais, destacando a natureza heterogênea desse distúrbio. Além disso, infelizmente, as drogas epiléticas mais antigas têm muitos efeitos colaterais, sendo o comprometimento cognitivo o principal efeito colateral que afeta a vida diária de pessoas com epilepsia. Modelos animais apropriados são essenciais para investigar os mecanismos patológicos desencadeados por mutações genéticas implicadas na epilepsia e para desenvolver terapias específicas e direcionadas. No entanto, os modelos de doenças do zebrafish (Danio rerio) são relevantes para a fisiopatologia das doenças humanas. Nos últimos anos, o zebrafish emergiu como um valioso organismo vertebrado para modelar epilepsias, com o uso de manipulação genética ou exposição a drogas epileptogênicas conhecidas, como o pentilenetetrazol (PTZ), para identificar novas terapêuticas antiepilépticas. O objetivo do presente estudo foi realizar uma revisão sistemática da literatura de modo a compreender de que forma zebrafish vem sendo utilizado para o estudo da epilepsia. Para tanto, foi feita uma pesquisa da literatura nas bases de dados Medline, Lilacs, Science, Citation Index, SciELO, PUBMED, Google Acadêmico, Periódicos CAPES e BVS Bireme. As palavras-chave utilizadas foram: "Suppression of the epileptic crisis", "Animal Model", "Zebrafish" nas bases de dados. Como resultados, foi possível observar 16 artigos incluídos após a síntese qualitativa, destes, $44 \%$ dos artigos analisaram determinado fármaco no tratamento da epilepsia, 30\% tratavam sobre a indução de epilepsia para estudo das vias envolvidas nesta doença, 22\% realizou estudos estritamente envolvidos à Síndrome de Dravet. Em conclusão, pode-se afirmar desenvolver um modelo animal para distúrbios cerebrais, particularmente epilepsia, é muito difícil devido à complexidade da doença. A maior parte da pesquisa pré-clínica da epilepsia tem se concentrado em roedores. Porém, pesquisas recentes apontam o zebrafish como um excelente alvo de análises laboratoriais, pois possui uma grande semelhança com os mamíferos e é altamente vantajoso com suas propriedades únicas, como fertilização externa, tamanho pequeno, bem como clareza ótica dos

embriões. O papel central dos receptores na epilepsia demonstra a utilidade potencial dos alvos para controlar as convulsões nesses modelos animais.

Palavras-chave: Epilepsia. Modelo Animal. Supressão da Crise Epilética. Peixe-Zebra.

\section{INTRODUCTION}

Epilepsy is a neurological disorder characterized by spontaneous and unpredictable seizures due to excessive abnormal neuronal activity in the brain, affecting more than 70 million people worldwide (I).

In addition to seizures, people with epilepsy often experience cognitive and psychological impairment, generalized social stigma and early death. However, little is known about the mechanism involved in epileptogenesis, but ample evidence suggests a pathogenic role of brain inflammation in epilepsy. $(2,3)$.

There are three primary treatment modalities for epilepsy: anticonvulsant drugs (ASDs), resective or palliative surgeries and neurostimulation. The first line approach is ASDs. However, this treatment is only effective in treating seizures and not the underlying epileptic disorder. In addition, ASDs usually cause adverse effects and one third of people with epilepsy develop drug resistance (4). 
Surgical removal or disconnection of an epileptic brain region may be more effective for drug-resistant focal epilepsy, but only a few patients are eligible for surgery ( 5 ).

Therefore, despite the long history of this field, innovative approaches to prevent or stop epileptogenesis are still needed. For this, a good experimental model is essential $(2,3)$.

The ideal animal model of epilepsy should reflect the processes underlying the disorder in humans, including electrophysiological, neuroanatomical, biochemical and genetic factors. Rodents are usually the standard experimental models for epilepsy, as well as for many other diseases, but it should be borne in mind that all animal models are comparative (6).

The model chosen should be the most appropriate to address a specific research question, and the strengths and limitations of epilepsy models lie in how they recapitulate human epilepsy. Animal models other than rodents are becoming increasingly important, as they have complementary advantages for studying epileptogenesis and evaluating treatments (7).

The zebrafish (Danio rerio) began to receive attention as a valid animal for studying epilepsy in 2005, when it was shown that they could express chemically induced seizure phenotypes (8). Since then, the zebrafish has established its role as a desirable alternative to rodents.

Brains of more complex mammals and organisms for the purposes of genetic modeling, including zebrafish, have been widely studied and zebrafish has gained great popularity in behavioral neuroscience and research in psychopharmacology (9)

In addition, the zebrafish model system offers large-scale screening and resembles the complexity of the central nervous system (CNS) (Io). Interestingly, the genetic compositions of zebrafish are comparable to humans with $70 \%$ genetic similarity, while $84 \%$ of the genes known for human diseases are widely expressed in zebrafish (II).

In addition, the zebrafish model is economically compared to rodents (I2), which strengthens its usability to fit neuroscientific research.

Due to its small size, oviparous development and transparency in the early stages of development, zebrafish has emerged as a valuable vertebrate organism to model human diseases as diverse as cardiovascular, cancer or neurological diseases (13).

Zebrafish combines the advantages of a vertebrate, including the high conservation of the organ architecture and the genetic code, with the small size and ease of genetic manipulation of simpler model organisms, thus facilitating fundamental studies and translational applications.

In particular, its automated high-throughput behavior screening ability and fluorescent markers of cellular processes have made zebrafish a particularly attractive model for epilepsy research. 
This was demonstrated by a large increase in the last decade in the number of publications with chemically induced and / or genetic models of epilepsy (II,I4-I6) and, more recently, reports of promising therapies obtained from chemical screens in these models ( $13,17-21)$.

Therefore, the objective of the present study was to carry out a systematic review of the literature in order to understand how the zebrafish animal model has been used for different therapeutic approaches to suppress the epileptic seizure.

\section{Materials and methods}

\section{Search Method}

The development of this systematic review was based on a survey of literature data, published in the period between 2017 and 2021. The scientific databases used were Medline, Lilacs, Science, Citation Index, SciELO, PUBMED, Google Scholar, CAPES and BVS Bireme Journals. In the searches, the following descriptors, in English, were considered: "Suppression of the epileptic crisis " AND " Animal Model " AND " Zebrafish ". Logical operators "AND”, "OR”, "AND NOT" were used to combine the descriptors and terms used to track publications. Was first done to generate a list of relevant articles for each database. This was done by first screening through the abstracts of the generated results, before proceeding to full text screening of potentially highly relevant articles. Through this search method and following the recommendations of PRISMA (Main Items for Reporting Systematic Reviews and Meta-analyzes), at first, potentially eligible publications were identified to be part of this review. Then, the articles that met the following inclusion criteria were distinguished: (a) electronic bibliographies compatible with the descriptors listed above; (b) chronology from the year 2017; (c) full texts and thesis-type abstracts, original articles, systematic reviews, books, normative instructions and ordinances of official scientific bodies, obtained from indexing platforms and scientific databases in the aforementioned area. It was decided not to include articles from narrative reviews, since they do not contemplate the analytical criticality estimated by.

\section{Study Selection and Inclusion Criteria}

Studies that were searched and considered for the systematic review were limited to original research articles as other publications (symposiums, conferences, editorials, book chapters, reviews and systematic reviews) would not provide sufficient information for evaluation and comparison. Any duplicated articles from the different databases were removed and articles that have no relevance to the importance of non-mammalian models for epilepsy research were also excluded. The selection of studies was conducted as per PRISMA guidelines (22). 
The initial search based on the keywords mentioned in the methodology yielded a total of 6,652 records. After applying exclusion criteria, total articles removed were 6,620, which includes; (a) 3,156 non-original research articles (b) 2,064 articles not related to animal models used in epilepsy research, (c) 400 duplicates, (d) I,or6 full text articles not relevant to the aim of the review (Figure I).

Sixteen eligible articles were included, compiled in Table I and discussed in the present systematic review. Based on the inclusion criteria, the final articles selected for evaluation consist of these, $44 \%$ of the articles analyzed a certain drug in the treatment of epilepsy, 30\% dealt with the induction of epilepsy to study the pathways involved in this disease, $22 \%$ carried out studies strictly involved in Dravet's Syndrome. A brief overview of all uses of zebrafish as models for researching epilepsy in our review is summarized graphically in Table I.

Fig I. Flow chart of study selection criteria based on preferred reporting items for systematic reviews and meta-analyses (PRISMA) guidelines.

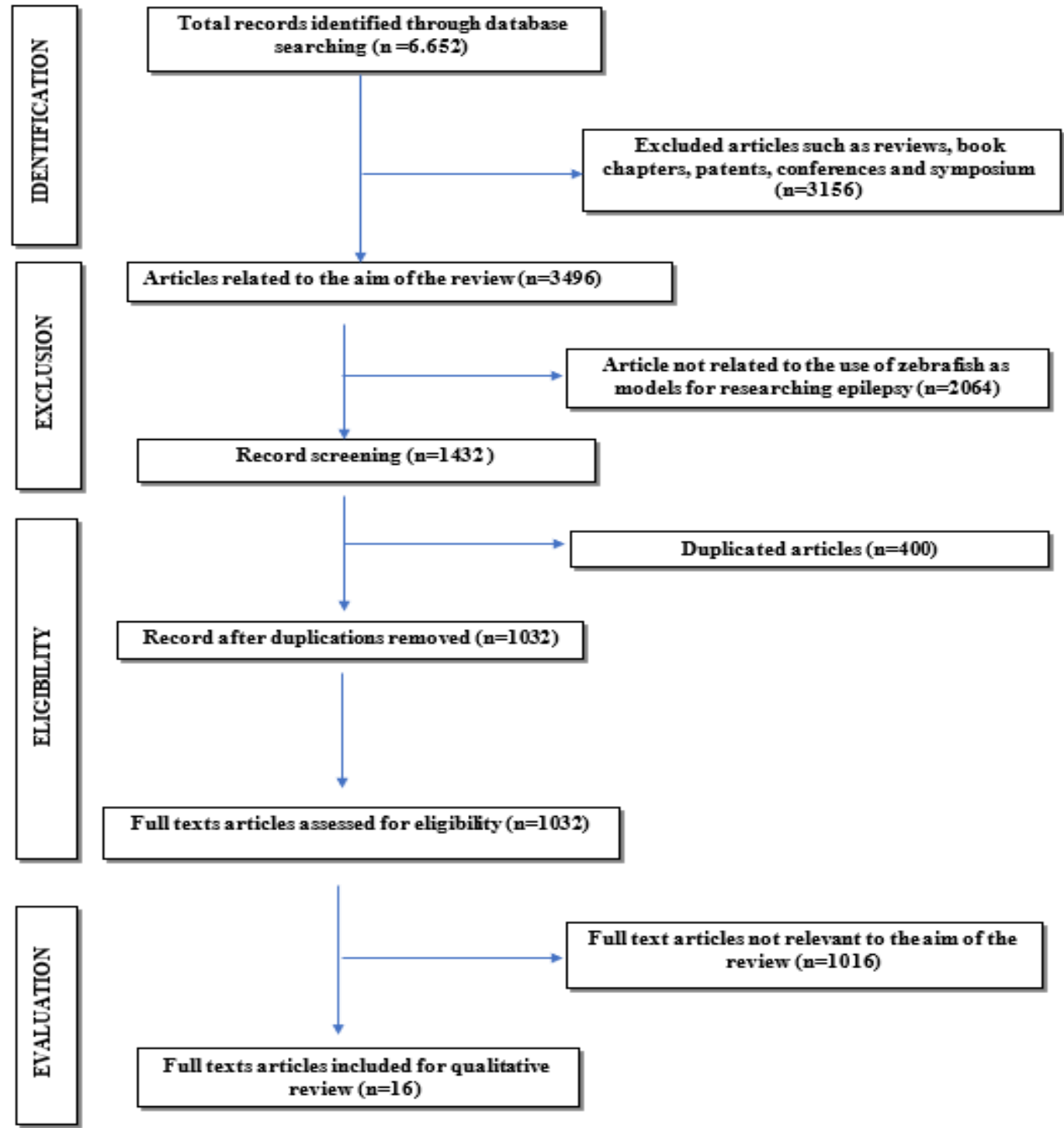


Revista Ibero- Americana de Humanidades, Ciências e Educação- REASE

open 2 access 
Revista Ibero- Americana de Humanidades, Ciências e Educação- REASE ${ }_{\text {open }}$ Access

Tabela 1. Demonstrativo dos artigos que integram a Revisão Sistemática da Literatura

\begin{tabular}{|c|c|c|c|}
\hline $\begin{array}{l}\text { Publication } \\
\text { Year }\end{array}$ & Study Objective & Study Results & Reference \\
\hline 2020 & $\begin{array}{l}\text { Generate and characterize a new zebrafish model for testing compounds } \\
\text { that selectively activate or inhibit the human NaVI.I or NaVI.6 channel. }\end{array}$ & $\begin{array}{l}\text { There was a selective inhibition of } \mathrm{NaV}_{\mathrm{I}} \mathrm{6} \text { and this proved to be as efficient as the selective } \\
\text { activation of } \mathrm{NaV} \text { I.I. Yes, this strategy may be viable as a new strategy for Dravet's syndrome and } \\
\text { other epilepsies of genetic origin. }\end{array}$ & (II) \\
\hline 2020 & $\begin{array}{l}\text { Develop a condition similar to a chronic seizure induced by pilocarpine in } \\
\text { adult zebrafish and investigate modulation in several neuroinflammatory } \\
\text { and neurotransmitter genes after exposures to pilocarpine. }\end{array}$ & $\begin{array}{l}\text { The administration of pilocarpine in repeated dose produces effects similar to chronic seizures, } \\
\text { maintaining an average above } 2 \text { seizures per day for a minimum of ro days with increased } \\
\text { expression of HMGB, TLR4, TNF- } \alpha \text {, IL-I, BDNF mRNA, CREB-I and NPY and decreased NF- } \\
\text { КB. }\end{array}$ & (14) \\
\hline 2020 & $\begin{array}{l}\text { It describes the method involved in the generation of the DEPDC5 loss of } \\
\text { function model and illustrates the protocol for assessing motor activity at } \\
28 \text { and } 48 \text { h post-fertilization (hpf), recording the field activity in the } \\
\text { zebrafish optical tectum. }\end{array}$ & $\begin{array}{l}\text { The described protocol provides a standardized and simple method to assess motor behavior and } \\
\text { neuronal field activity, via recording of extracellular current clip voltage together with the } \\
\text { automatic detection of depolarization events in the optical tectum, to characterize epileptiform-like } \\
\text { phenotypes in zebrafish models. }\end{array}$ & (13) \\
\hline 2020 & $\begin{array}{l}\text { Synthesize two derivatives of berberine (BBR-DI and BBR-D2) to compare } \\
\text { their effect of reducing seizures with BBR in zebrafish-induced } \\
\text { pentylenetetrazole (PTZ) seizures. }\end{array}$ & $\begin{array}{l}\text { Of the compounds tested, BBR-DI (hydrophilic berberrubine) showed the strongest seizure- } \\
\text { reducing effect. }\end{array}$ & (20) \\
\hline 2020 & Develop a system to record EEG of several adult zebrafish simultaneously. & $\begin{array}{l}\text { PTZ seizure induction and VPA seizure suppression were successfully detected through EEG } \\
\text { recording. }\end{array}$ & $(2 \mathrm{I})$ \\
\hline 2020 & $\begin{array}{l}\text { Develop a microfluidic chip capable of uniform and continuous drug } \\
\text { infusion in all microfluidic channels during EEG recording. }\end{array}$ & $\begin{array}{l}\text { The microfluidic system developed can contribute to the mass screening of EEG for the } \\
\text { development of drugs to treat neurological disorders, such as epilepsy, in a short time, due to its } \\
\text { accessible size, cheap manufacturing cost and uniform drug infusion guaranteed in all channels } \\
\text { without environmental-induced artifacts. }\end{array}$ & (9) \\
\hline 2020 & $\begin{array}{l}\text { To analyze the evidence that epilepsy is characterized by disorders in } \\
\text { mitochondrial function and the advantage of using bioenergetics as a } \\
\text { functional reading test to discover new ASDs. }\end{array}$ & Bioenergetics is interrupted in epilepsy, which can be explored for phenotypic screening. & (23) \\
\hline 2019 & $\begin{array}{l}\text { Investigate the serotonin receptors that could moderate this antiepileptic } \\
\text { activity. }\end{array}$ & $\begin{array}{l}\text { Three clemizole analogs with binding to the } 5 \text {-HT receptor have been found to exert powerful } \\
\text { antiepileptic activity. Based on structure-activity relationships and analysis based on medicinal } \\
\text { chemistry, it was possible to observe an additional set of known } 5 \text {-HT receptor specific drug } \\
\text { candidates. }\end{array}$ & (24) \\
\hline 2019 & $\begin{array}{l}\text { To evaluate the effects of Rongchang and Xifeng capsules on } \\
\text { pentylenetetrazole-induced epilepsy in zebrafish larvae. }\end{array}$ & $\begin{array}{l}\text { There is effectiveness of the Rongchang and Xifeng capsule in relieving epilepsy-like behavior and } \\
\text { molecular responses. }\end{array}$ & $(25)$ \\
\hline 2019 & $\begin{array}{l}\text { Identify the first cell defects underlying the onset of seizures } \\
\text { (epileptogenic period) during the development of the perinatal brain in a } \\
\text { new zebrafish model of Dravet's syndrome (DS). }\end{array}$ & $\begin{array}{l}\text { The remarkable efficacy of fenfluramine (FEN) in this DS model demonstrates the usefulness of } \\
\text { zebrafish in discovering the potential disease-modif } 9 \mathrm{Q} \text { d activity of drugs conducted. }\end{array}$ & (15) \\
\hline 2019 & $\begin{array}{l}\text { Analyze the anticonvulsant effects of } \alpha \text {-asaronol, a metabolic product of } \alpha \text { - } \\
\text { asarone, in seizures induced by pentylenetetrazole (PTZ) in zebrafish and } \\
\text { investigate the underlying mechanisms. }\end{array}$ & $\begin{array}{l}\text { PPAR } \gamma \text { has been reported for the first time to be associated with epileptic seizures in the zebrafish, } \\
\text { supporting earlier evidence that zebrafish is a suitable alternative for studying seizures. }\end{array}$ & (17) \\
\hline
\end{tabular}




\begin{tabular}{|c|c|c|c|}
\hline 2019 & $\begin{array}{l}\text { To evaluate the effectiveness of Embelin (EMB) against acute seizures } \\
\text { induced by pentylenetetrazole (PTZ) and its associated cognitive } \\
\text { dysfunction. }\end{array}$ & $\begin{array}{l}\text { EMB suppresses seizure-like behavior via the GABA A receptor pathway and has a positive impact } \\
\text { on cognitive functions. And, it can be a promising molecule for learning and memory dysfunction } \\
\text { induced by epilepsy. }\end{array}$ & $(26)$ \\
\hline \multicolumn{4}{|c|}{ To be continued } \\
\hline Publication & Study Objective & Study Results & Reference \\
\hline 2019 & $\begin{array}{l}\text { Determine whether new antiepileptic drugs (AEDs) (Zonisamide, } \\
\text { Levetiracetam, Perampanel, Lamotrigine and Valproic Acid) also cause } \\
\text { cognitive impairment, using a zebrafish model. }\end{array}$ & $\begin{array}{l}\text { Cognitive function was impaired in zebrafish treated with AED, regardless of whether or not seizure } \\
\text { was induced. In addition, it was possible to observe a decrease in glutamate levels in the brain due } \\
\text { to treatment with AED and this may be one of the main factors responsible for the cognitive } \\
\text { impairment observed. }\end{array}$ & (27) \\
\hline 2019 & $\begin{array}{l}\text { Understand the mechanisms related to neuronal hyperexcitation in } \\
\text { ScniLab depleted larvae. }\end{array}$ & $\begin{array}{l}\text { Loss of ScniLab function causes neuronal overexcitation as a result of disturbed synaptic balance } \\
\text { and increased neuronal apoptosis. }\end{array}$ & $(28)$ \\
\hline 2018 & $\begin{array}{l}\text { Compare the transient treatment with pentylenetetrazole (PTZ) in } \\
\text { zebrafish larvae with a more sensitive zebrafish model for epilepsy with } \\
\text { predictable and recurrent seizures. }\end{array}$ & $\begin{array}{l}\text { The new method generated predictable recurrent seizures not triggered by drugs in response to } \\
\text { intermittent photic stimulation in zebrafish larvae and can serve as a sensitive method for } \\
\text { screening for antiepileptic drugs or a new research protocol in epilepsy research. }\end{array}$ & (4) \\
\hline 2017 & Develop a zebrafish model of epilepsy-induced cognitive dysfunction. & $\begin{array}{l}\text { All AEDs significantly reversed PTZ-induced seizures in zebrafish, but had a negative impact on } \\
\text { zebrafish's cognitive functions. }\end{array}$ & $(29)$ \\
\hline
\end{tabular}




\section{RESULTS AND DISCUSSION}

Of a total of 6,652 articles, i6 met the inclusion criteria. The following is general information about the 16 included studies, published in the period from 2017 to 2021, (Figure 2). In the period corresponding to the research, from 2017 to 2021, there was a gradual increase in the number of publications associated with different therapeutic approaches for the suppression of the epileptic seizure that use zebrafish as a model organism.

The lower number of publications in 2017 is explained by the smaller period considered for the research in those years, and in 202I, by the fact that the research was carried out at the beginning of that year.

This increase in publications can be attributed to international programs and projects in the active search for alternative models following the trends of modernity toxicity test (30). The publication of the genome research in 2013 (31), may also have played a role in improving comparison and extrapolation to humans. The availability of transgenics and elimination lines has also stimulated an increase in the use of zebrafish in biomedical research $(32,33)$.

Finally, the increase in publications can also be attributed to the publication of new guidelines for zebrafish toxicity tests, such as the OECD FET test.

An overview of the geographic origins of the first authors can be found in Figure 3. USA, China, Canada, Malaysia and Brazil are the main countries. In Table 2, we can identify the Distribution of the Classification of Articles according to the Qualis evaluated by the Sucupira Platform.

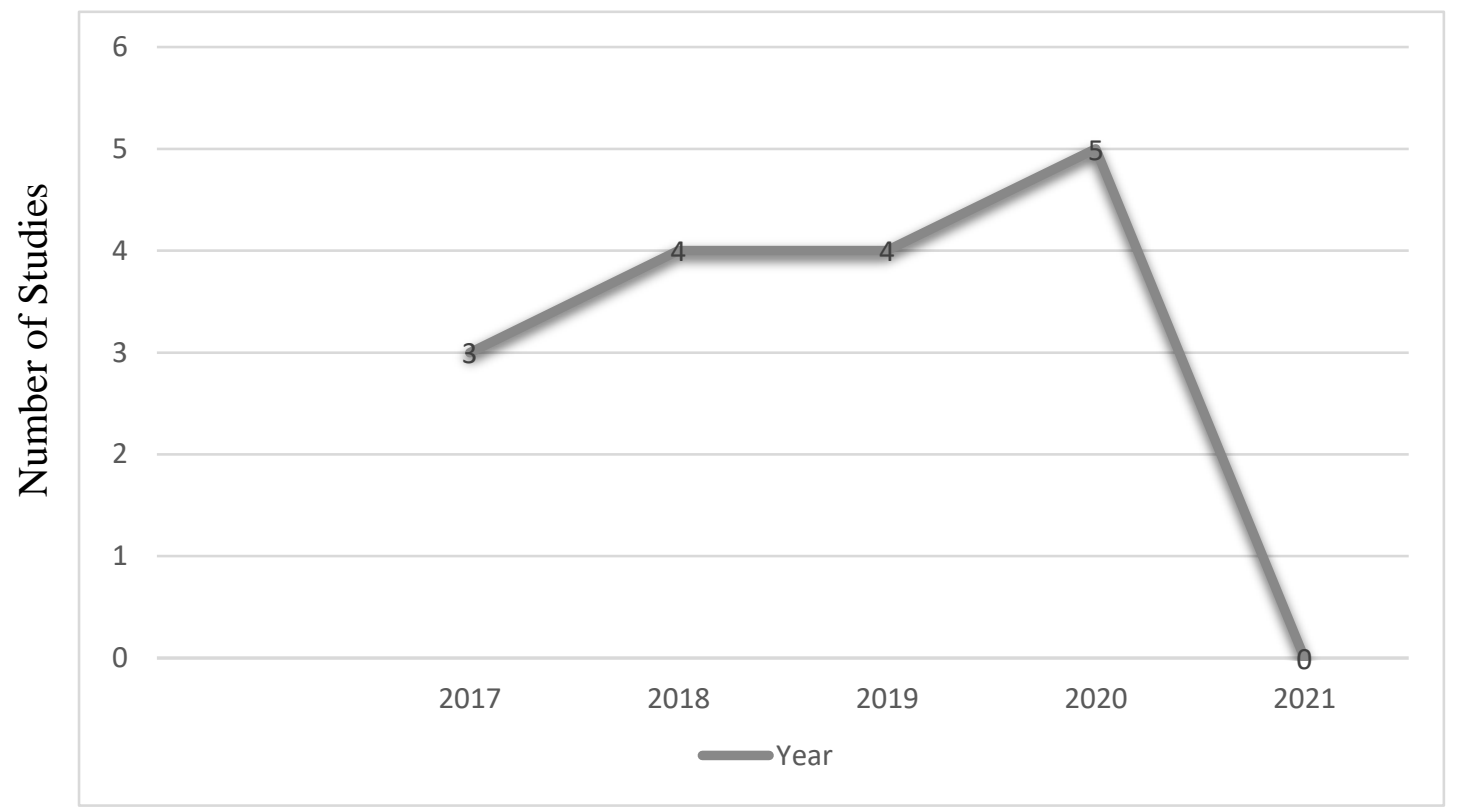

Fig. 2 Number of articles resulting from the search by using the keywords covering the period from I january 2017 to I january 2021. 


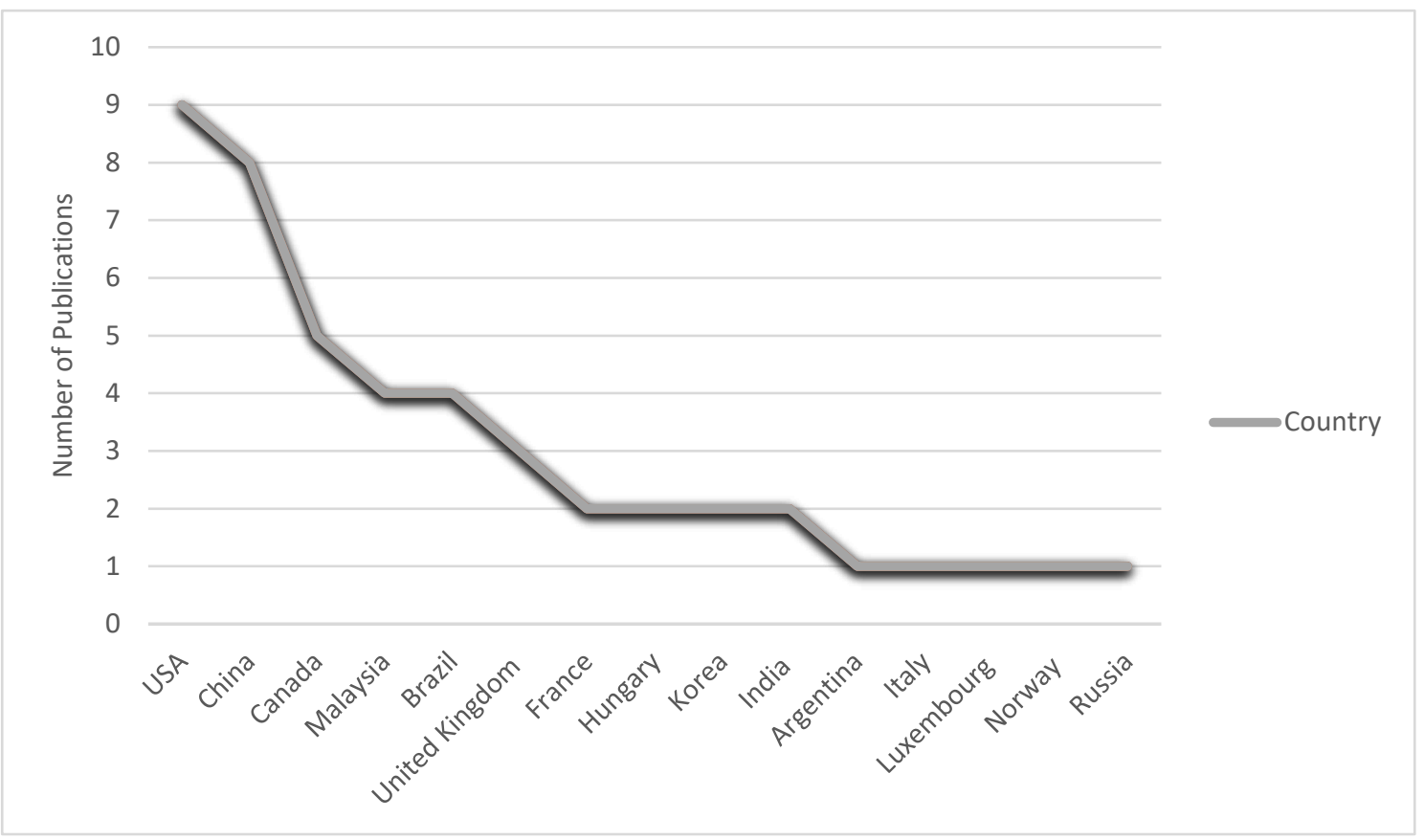

Fig. 3 Geographical origins of articles' authors

\section{Zebrafish (Danio rerio)}

Zebrafish are considered adults from 90 days after fertilization (dpf) and are sexually active until death. They breed all year round and a single female can lay hundreds of eggs a week (34).

Zebrafish embryos grow externally, and the larvae are highly transparent until 2-3 weeks of development, allowing for exceptionally detailed visualization of their embryogenesis and central nervous system (35).

In addition, embryonic zebrafish are subject to traditional and modern genome engineering approaches in an easier, cheaper and faster way, such as those that use, RNA interference, capped synthetic mRNA injection, expression plasmid injection, nucleases from zinc finger (ZFNs), transcription activator such as effector nucleases (TALENs), and regularly spaced short palindromic repetitions (CRISPR) (36).

Zebrafish do not need to be fed up to $6 \mathrm{dpf}$ and absorb the drug compounds directly from the medium in which they are inserted. The larvae can, therefore, be kept in plaques and their behavioral symptoms can be monitored by video tracking devices (36).

While zebrafish larvae exhibit dynamic changes through their ontogenesis, adult zebrafish are physiologically more stable. The adult zebrafish has a full range of complex brain functions with superior behavior and integrated neural functions, including memory, 
conditioned responses and social behaviors (37). These differences between larvae and adults can lead to differences in the results of drug screening.

Much of the research on epilepsy has so far been carried out on rodents and on human tissue obtained during surgical resection for intractable epilepsy (38).

However, zebrafish has emerged as an excellent animal model for several neurological diseases, including epilepsy $(29,39)$. Several researches are emerging that promote the use of laboratory $z \mathrm{bf}$ until then underutilized in neuroscience and neuropharmacology (40).

It is possible to change the genetic architecture of zebrafish so that it mimics epilepsy, and thus to test the mechanisms of various drugs. With this new phenotype, fish produce epileptic attacks measured in the zebrafish brain through the local field potential (LFP) (4I).

And, depending on the technique used to form new zebrafish models, it changes genetically and probably transcriptionally, thus being able to generate different degrees of mutations (II).

Research results can be translated for mammals, particularly humans, as more than $70 \%$ of zebrafish genes are substantially similar to their mammalian orthologists (26).

Another reason is that $70 \%$ of the zebrafish genes also have one or more human orthologists and $47 \%$ of the human genes have a one-to-one relationship with a corresponding zebrafish gene $(16,17)$.

There are also studies that have established that the zebrafish brain regions show functions homologous to their mammalian counterparts, despite important neuroanatomical differences (9-11,13-17,19-21,24,27,28,42,43).

Thus, recent studies have shown that many different models of genetically modified zebrafish are used as initial in vivo screening tools for compounds derived from natural sources (10,13,16,21).

\section{Epilepsy overview}

Epilepsy is a neurological disease with a large number of etiologies that are beginning to be unraveled with the advent of genetic sequencing technologies $(44-46)$.

Although pharmacological agents are the basis of treatment for seizure control, inflexible $30-40 \%$ of patients remain refractory to these drugs and continue to experience spontaneous recurrent seizures with cognitive, behavioral and mental problems throughout their lives, as well as increased risk sudden unexpected death (I6).

Despite more than eight decades of discovery of anticonvulsants (ASD) and the approval of dozens of new drugs, the percentage of this refractory population remains 
practically unchanged, suggesting that drugs with new and unexpected mechanisms of action are necessary (16).

Therefore, animal models are essential for efficient analysis that will produce both knowledge about the pathological mechanisms of epilepsy and therapies aimed at the different forms of this condition.

The zebrafish models have been very efficient in reproducing the characteristics of epilepsy as well as in providing reliable information for the development of antiepileptic drugs $(35,47)$.

The first symptoms of epilepsy are abnormal neuronal discharges, which cannot be modeled in cell culture (48-50).

Thus, in vivo animal models without ethical restrictions or with minimal ethical restrictions are the ideal tools for investigating the underlying mechanisms of epilepsy (20).

In addition, the minimal amount of drugs needed for testing, the short periods of testing used in trials, the manifestation of seizure-like behavior, the possibility of EEG recordings, and the transparent nature make zebrafish the animal model, in vivo, of choice in numerous studies focused on epilepsy (34,5I).

In this way, it is possible to detect spontaneous seizures in zebrafish $(52-55)$. In addition, neurophysiological analyzes in these models (35) confirmed the neuronal basis of epileptic behavior $(56,57)$.

Thus, it is possible to detect simple behaviors, such as spontaneous swimming, which allows the rapid detection of therapeutic potentials (13).

\section{Dravet syndrome}

Childhood severe myoclonic epilepsy (SMEI) is currently known as Dravet's syndrome (DS), it is a severe form of epilepsy. However, current medication strategies remain inefficient.

However, promising new drugs that act on the serotonin pathway, such as Fenfluramine (FA), show effectiveness in reducing seizures in $50 \%$ to $90 \%$ of patients (80).

However, the side effects of drugs may still limit their use, underscoring the need for new drug discoveries.

To best mimic the genetic architecture of DS in human patients, the animal model must exhibit a 50\% haploinsufficiency of SCNIA. Haploinsufficiency describes a model of dominant gene action in diploid organisms, in which a single copy of the standard allele in a 
locus in heterozygous combination with a variant allele is insufficient to produce the standard phenotype (II).

Possibly, the zebrafish has two orthologs for the human SCNIA gene; ScniLaa and ScniLab. Although the expression of these genes cannot be observed in embryonic phases, but only in larval stages (8I), these genes have a structural role in the genetic engineering of epilepsy (80).

Orthologists are genes in different species developed from a common ancestral gene. Parallels are copies of genes created by a duplication event within the same genome. While orthologous genes maintain the same function, paragon genes often develop different functions due to the lack of selective pressure on a duplicate copy of the gene (II).

In addition, three other ScniLab zebrafish models were introduced in 2010, generated from a mutagenesis of $\mathrm{N}$-ethyl-N-nitrosourea (ENU) (8r.82) or antisense morpholino (MO) oligomers (83).

All three carry an epileptic phenotype that includes epileptiform activity and hyperactivity seen in the brain. However, CRISPR / Casg is the most efficient technique to specifically interrupt the gene that is the target, in recent times, unlike the ENU mutagenesis (84), it acts on DNA instead of exercising its role in protein, using, MO-based approaches (85) thus allowing the elaboration of animal models that best mimic the genetic architecture of this disease.

The epileptic phenotype and drug response in zebrafish larvae can be measured by quantifying high velocity burst movements which are indicative of epileptic seizures in fish.

Thus, the effect of antiepileptic drugs coincides with the reduction of brain peaks in this phenotype, which could be proven through the analysis of a local field potential (LFP) set-up (85).

Peak LFP events, however, should not be confused with single neuron spikes, as they indicate the synchronized activity of a large number of cells (II).

\section{Effects on memory}

The use of AEDs can generate cognitive impairment in zebrafish negatively affecting cognitive function, including combinations of AEDs that are used in clinical practice. Although this loss of learning and memory capacity is undoubtedly multifactorial, a decrease in glutamate levels in the brain as a result of the tested AEDs appears to be a major factor (27). 
Thus, future work can focus on other forms of memory and other animal species to determine whether this pattern is also true (27). The Knockouts ScniLab animals showed behavior comparable to the knock-down ScniLab models described previously $(8 \mathrm{r}, 83,86)$ in addition to hyperactivity and high speed swimming movements.

The fast swimming movements (> $50 \mathrm{~mm} / \mathrm{s}$ ) were separated from the regular locomotive data to produce a test of high speed swimming movements and this analysis was performed by optimized parameters (II).

ScniLab knockouts showed a significantly higher number of high-speed swimming movements. Using the nisb-WT control zebrafish, it was found that explosion movements are unique to ScniLab knockouts and are not caused by the absence of an inflated swimming bladder.

No spontaneous explosion movement was observed in ScniLab heterozygous knockout larvae. Using an LFP configuration for zebrafish larvae (I4), abnormal brain activity was observed in ScniLab knockouts, including multiple high-frequency single-and poly spiking electrical discharges. The epileptiform activity recorded from ScniLab knockouts is similar to those observed in previous KnILab zebrafish models $(8 \mathrm{r}, 83)$.

It is possible to mimic the haploinsufficiency of SCNIA in humans, which probably affects local GABA levels, leading to susceptibility to attacks in patients with DS (II).

It is possible to observe a pharmacological response comparable to that observed in most patients with DS by doing this through selective ion channel subtype inhibition or activation and these studies are beneficial in epilepsy (II).

Today, there are 4 types of mutations performed on the zbf to mimic epilepsy in these animals, but depending on the amount of ion channels produced by the genetic mutations, one type of animal may respond differently to the same quantities of medications (II).

Therefore, it is necessary to understand the reason for these variations in order to standardize the use of animals, but specifically which technique will be used to induce gene mutations (II).

However, zebrafish orthologists for some protein subunits are well conserved, reaching $85 \%$ of DNA and protein identity, highlighting that inhibitors of certain proteins could be properly tested, but the results should be interpreted with caution (II).

In summary, new compounds tested in zebrafish should always be further studied in other models, preferably of human origin. It is necessary that new drugs are developed with the purpose of acting at the nucleotide level in order to improve the treatment of genetic epilepsy in order to reach activation or inhibition with better selectivity and potency (II). 
And, the treatment of DS must be at the level of the genome or transcriptome, since its disorders have a genetic cause (II).

Zebrafish larvae that have lost function of the scniLab gene, one of two SCNIA zebrafish orthologists, have already been used as animal models to find new candidates for antiepileptic drugs, several of which are now in clinical trials (28).

However, although the larvae with ScniLab alterations have been established as a model of genuine epilepsy, the spectrum of neuronal deficits induced by the loss of function of this sodium channel has not yet been fully explored.

Larvae with alterations with ScniLab, have massive synchronous calcium absorptions and explosions of local field potential, characteristics of epileptiform crises (28).

\section{Use of the Electroencephalogram (EEG)}

The electroencephalogram (EEG), directly measures brain activity, is used to diagnose and analyze neurological disorders. Previous studies have recorded EEG signals from adult zebrafish, but the recordings were only possible from a single animal (2I).

However, it was possible to develop a system to record EEG of several adult zebrafish simultaneously. To ensure that several zebrafish were in a stable condition for a certain time, the infusion and recording systems must be mechanically separated, which allows the fish to be effectively immobilized (2I).

The developed system can effectively measure the individual EEG signals of more than three animals in each environment simultaneously, on average. PTZ seizure induction and VPA seizure suppression were successfully detected through EEG recording (2I).

The microfluidic EEG system that can detect EEG of several larvae simultaneously, creating a microfluidic chip to hold the larva in a stable way and change the liquid uniformly in all channels (9).

Through the branch-shaped microfluidic channels, the liquid could be filled uniformly with the same gradient along the channels, even with the larvae contained within it (9).

The microfluidic chip achieves stable fixation of fish during EEG recording, without using any additional means, such as agarose, unlike previous studies (9).

In addition, the fish can be exposed to multiple drugs sequentially during EEG recording without any disturbances that could affect the EEG signal. It is possible to register EEG signals from 4 fish at a time for 60 min, which reduces the experimental time and drug consumption to a quarter per fish (9). 
A success rate of $75 \%$ can be achieved in the EEG record. However, if the movement of the electrodes can be adjusted more precisely, the number of measurable fish and the success rate will be improved (9).

And, this allows for sequential drug screening as long as the fish remain in a stable aquatic environment. In addition, responses to drugs can be observed immediately, since drugs can be exposed directly to fish due to the continuous flow through the developed microfluidic chip, unlike the cases that use agarose to fix the larvae (9).

The developed EEG system is expected to improve efficiency in detecting EEG for drug screening to treat neurological disorders such as epilepsy, thanks to its small size, low manufacturing cost and guaranteed uniform drug infusion across all channels without artifacts induced by the environment (9).

\section{Traditional Chinese medicine}

Rongchang is a Chinese patented medicine developed by Professor MA Rong. It was developed to relieve the cognitive impairment caused by epilepsy and also to control the onset of that disease, in addition to being beneficial for the development of cognitive function intelligence based on antiepileptic action. The Xifeng capsule also has an antiepileptic effect. The composition of Chinese patented medicines is complex and their means of production and the proportion of herbs in traditional Chinese medicine are confidential. The Rongchang capsule and the Xifeng capsule are effective for the treatment of pediatric epilepsy (25).

The relationship between epilepsy and sleep is controversial and bidirectional, as lack of deep sleep can cause seizures. In turn, seizures and antiepileptics can probably disrupt sleep architecture. Some antiepileptic drugs can cause drowsiness, while others can lead to insomnia (25).

An example of this is that, first generation AEDs, such as phenobarbital, phenytoin, barbiturates and benzodiazepines, tend to cause interruption of night sleep, increasing the number of awakenings and promoting daytime sleepiness (25).

Rongchang and Xifeng capsules change the larvae's resting / waking behaviors. They cause insomnia at night and increase locomotor activities during the day, increasing the number of rest sessions and decreasing the duration of the rest session (25).

Xifeng significantly promotes an increase in daytime larval activities while Rongchang does not. In addition, the correlation between Rongchang capsule and Xifeng was investigated for this purpose, eight signaling pathways (adrenergic, serotonin, dopamine, 
GABAergic, melatonin, histamine, adenosine and glutamate signaling) were analyzed for correlation analyzes with experimental capsule concentrations (25).

The capsules showed a high correlation with some compounds in some pathways, such as adrenergic, serotonergic, gabaergic, histamine and glutamate signaling. AEDs are not fully responsible for sleep disorders, however, understanding their impacts can help optimize treatment plans to avoid unnecessary worsening of sleep quality (25).

For children, improving sleep efficiency can contribute to suppression of seizures and recovery from epilepsy and also brain development (25).

\section{Mitochondrial bioenergetic analysis}

The measurement of mitochondrial bioenergetics should be added to this growing list of functional reading assays in epilepsy.

Mitochondria participate in almost all aspects of cell homeostasis, from the production of ATP and biosynthetic intermediates, to responding to cell stress and initiating autophagy and apoptosis, even regulating communication between cells (92).

Due to its central role in the physiology of an organism, it is perhaps not surprising that mitochondrial dysfunction is now a striking feature of many, an example of which is epilepsy $(93,94)$.

For most of these diseases, mitochondrial dysfunction is not a mere factor involved, but the focus of the manifestations of the disease and, therefore, breakdowns in mitochondrial production indirectly inform about the disease state (95).

Thus, mitochondria contribute to the etiology of disparate pathologies $(96,97)$, thus supporting the intriguing notion that these shared mechanisms can converge drug discovery.

In fact, screening for agents that improve general cellular bioenergetics offers a promising alternative approach to discovering new drugs not only for the treatment of epilepsy, but in a myriad of CNS disorders where drug discovery has been frustratingly slow.

Finally, since these metabolism-based trials are impartial with respect to any particular target or pathway, this strategy has the potential to discover drugs with unexpected mechanisms of action, perhaps serving as a powerful tool to reach the persistent $30-40 \%$ of refractory epileptic patients.

In vivo bioenergetic screening is not feasible in rodents, so zebrafish is emerging as a key model in this approach. In fact, we can observe in the zebrafish, changes in metabolism in real time and details of the metabolic characteristics (98), being the starting point for research in this nature. 
A zebrafish with Dravet's syndrome has altered metabolism, including changes in glycolysis and mitochondrial respiration, as well as negative regulation of various glycolytic enzymes (99).

\section{New way of inducing epilepsy in Zebrafish}

Treatment with pentylenetetrazole (PTZ) in zebrafish larvae has been widely accepted as a promising animal model for human epilepsy. However, this model is not ideal due to its lack of recurrent seizures, which are the main characteristics of epilepsy in human diseases (4).

Thus, it is important to develop a more sensitive zebrafish model for epilepsy with predictable and recurrent seizures (4).

The new protocol generated recurring responses after exposure of the animals to flashing lights 4 hours after PTZ treatment. The effects can be suppressed by the antiepileptic medicine valproic acid. The characteristics of visual stimuli play an important role in this new model (4).

The new method generated predictable recurrent seizures not triggered by drugs in response to intermittent photic stimulation in zebrafish larvae and can serve as a sensitive method for screening for antiepileptic drugs or a new research protocol in epilepsy research (4).

Such combined treatment of PTZ and visual stimulation for 3 days and successfully generated a model of recurrent seizures epilepsy that are sensitive to intermittent photic stimulation (IPS). The increase in locomotion activity after $30 \mathrm{~Hz}$ flashing light demonstrated its potential as a sensitive index to be used in screening for AED or to probe the neural networks involved in the onset and spread of crises (4).

Animal models cannot represent the complete pathology that is observed in human diseases. It is very difficult to develop an animal model for brain disorders, particularly epilepsy, due to the complexity of the disease and the variation between species (29).

However, when using a series of different techniques and parameters in zebrafish, a unique characteristic of the specific disorder can be incorporated to study the molecular and behavioral basis of this disease (29).

Therefore, behavioral study, analysis of neurotransmitters and studies of gene expression at work provide a first model for screening basic drugs in cognitive research related to epilepsy using zebrafish as an animal model (29). 


\section{Conclusion}

Animal models are considered a useful tool for investigating the cause and pathology of human diseases, but developing an animal model for brain disorders, particularly epilepsy, is very difficult due to the complexity of your disease.

However, it is known that zebrafish has a great similarity to mammals and are highly advantageous with their unique properties, such as external fertilization, small size, as well as optical clarity of the embryos.

The current study reinforces this possibility, developing a condition similar to chronic epilepsy in adult zebrafish after exposure to pilocarpine. Pilocarpine-induced epileptic zebrafish demonstrated behavioral changes,

This analysis may be even better if the seizures induced by pilocarpine and neuronal death are analyzed with electrophysiological records and histopathological findings.

Therefore, the current study by modeling a condition similar to a chronic seizure in an adult zebrafish using pilocarpine paves the way for future research.

Thus, the publication of many studies corroborates that zebrafish is an excellent model system to continue its use in understanding the mechanism of seizure generation, evaluating new anticonvulsants, in addition to being able to evaluate the therapeutic potential of the new antiepileptic therapy.

Therefore, the discovery of anticonvulsant drugs needs new approaches to discover therapeutic agents with unexpected mechanisms of action. And, zebrafish is an alternative model organism that has been established over the past 20 years and exhibits electrophysiological characteristics. Still, bioenergetics is interrupted in epilepsy, which can be explored for phenotypic screening.

\section{REFERENCES}

I. Barbalho PG, Carvalho B de S, Lopes-Cendes I, Maurer-Morelli CV. Cyclooxygenase-I as a potential therapeutic target for seizure suppression: Evidences from zebrafish pentylenetetrazole-seizure model. Front Neurol. 2016;7(NOV).

2. Feas DA, Igartúa DE, Calienni MN, Martinez CS, Pifano M, Chiaramoni NS, et al. Nutraceutical emulsion containing valproic acid (NE-VPA): a drug delivery system for reversion of seizures in zebrafish larvae epilepsy model. J Pharm Investig. 2017;47(5):429-37.

3. Grone BP, $\mathrm{Qu} \mathrm{T}$, Baraban SC. Behavioral comorbidities and drug treatments in a zebrafish scnilab model of dravet syndrome. eNeuro. 2017;4(4).

4. Sun S, Zhu C, Ma M, Ni B, Chen L, Zhu H, et al. A pentylenetetrazole-induced kindling zebrafish larval model for evoked recurrent seizures. bioRxiv. 2019;1-24.

5. Thijs RD, Surges R, O'Brien TJ, Sander JW. Epilepsy in adults. Vol. 393, The Lancet. Lancet Publishing Group; 2019. p. 689-70I. 
6. Turrini L, Fornetto C, Marchetto G, Müllenbroich MC, Tiso N, Vettori A, et al. Optical mapping of neuronal activity during seizures in zebrafish. Sci Rep. 2017;7(I):I-I2.

7. Jin M, Sheng W, Han L, He Q, Ji X, Liu K. Activation of BDNF-TrkB signaling pathway-regulated brain inflammation in pentylenetetrazole-induced seizures in zebrafish. Fish Shellfish Immunol. 2018;83:26-36.

8. Baraban SC, Taylor MR, Castro PA, Baier H. Pentylenetetrazole induced changes in zebrafish behavior, neural activity and c-fos expression. Neuroscience. 2005;131(3):759-68.

9. Lee Y, Seo HW, Lee KJ, Jang JW, Kim S. A microfluidic system for stable and continuous eeg monitoring from multiple larval zebrafish. Sensors (Switzerland). 2020;20(20):I-I5.

Io. Cho SJ, Park E, Baker A, Reid AY. Age Bias in Zebrafish Models of Epilepsy: What Can We Learn From Old Fish? Front Cell Dev Biol. 2020;8(September):I-8.

II. Weuring WJ, Singh S, Volkers L, Rook MB, Van't Slot RH, Bosma M, et al. NaVi.I and $\mathrm{NaV}$.6 selective compounds reduce the behavior phenotype and epileptiform activity in a novel zebrafish model for Dravet syndrome. PLoS One. 2020;15(3):1-17.

12. Kundap UP, Kumari Y, Othman I, Shaikh MF. Zebrafish as a model for epilepsyinduced cognitive dysfunction: A pharmacological, biochemical and behavioral approach. Front Pharmacol. 2017;8(AUG):I-13.

13. Calbiac H De, Dabacan A, Muresan R, Kabashi E, Ciura S. Behavioral And Physiological Analysis In A Zebrafish Model Of Epilepsy. 2020;(April):I-7.

I4. Paudel YN, Kumari Y, Abidin SAZ, Othman I, Shaikh MF. Pilocarpine induced behavioral and biochemical alterations in chronic seizure-like condition in adult Zebrafish. Int J Mol Sci. 2020;2I(7).

I5. Tiraboschi E, Martina S, van der Ent W, Grzyb K, Gawel K, Cordero-Maldonado $\mathrm{ML}$, et al. New insights into the early mechanisms of epileptogenesis in a zebrafish model of Dravet syndrome. Epilepsia. 2020;6I(3):549-6o.

I6. Ibhazehiebo K, Rho JM, Kurrasch DM. Metabolism-based drug discovery in zebrafish: An emerging strategy to uncover new anti-seizure therapies. Neuropharmacology. 2020;167(June 2019):107988.

17. Jin M, Zhang B, Sun Y, Zhang S, Li X, Sik A, et al. Involvement of peroxisome proliferator-activated receptor $\gamma$ in anticonvulsant activity of $\alpha$-asaronol against pentylenetetrazole-induced seizures in zebrafish. Neuropharmacology. 2019;162:107760.

18. Burrows DRW, Samarut, Liu J, Baraban SC, Richardson MP, Meyer MP, et al. Imaging epilepsy in larval zebrafish. Eur J Paediatr Neurol. 2020;24:70-80.

19. Thornton C, Dickson KE, Carty DR, Ashpole NM, Willett KL. Cannabis constituents reduce seizure behavior in chemically-induced and scnia-mutant zebrafish. Epilepsy Behav. 2020;110:107152.

20. Zhang B, Wang L, Ji X, Zhang S, Sik A, Liu K, et al. Anti-Inflammation Associated Protective Mechanism of Berberine and its Derivatives on Attenuating PentylenetetrazoleInduced Seizures in Zebrafish. J Neuroimmune Pharmacol. 2020;15(2):309-25.

21. Lee Y, Lee KJ, Jang JW, Lee S im, Kim S. An EEG system to detect brain signals from multiple adult zebrafish. Biosens Bioelectron. 2020;164(April):112315.

22. Moher D, Shamseer L, Clarke M, Ghersi D, Liberati A, Petticrew M SP, LA. S. Preferred reporting items for systematic review and meta-analysis protocols (PRISMA-P) 2015 statement. Syst Rev. 2015;4(I):I-I9.

23. Ibhazehiebo K, Rho JM, Kurrasch DM. Metabolism-based drug discovery in zebrafish: An emerging strategy to uncover new anti-seizure therapies. Vol. I67, Neuropharmacology. Elsevier Ltd; 2020. p. I07988.

24. Griffin AL, Jaishankar P, Grandjean J-M, Olson SH, Renslo AR, Baraban SC. Zebrafish studies identify serotonin receptors mediating antiepileptic activity in Dravet syndrome. Brain Commun. 2019;I(I). 
25. Zhang S, Xu J, Wang C, Feng D, Dai L, Kuang X, et al. Rongchang and Xifeng capsules suppress pentylenetetrazole-induced seizures and change rest/wake behavior in zebrafish larvae. J Tradit Chinese Med = Chung i tsa chih ying wen pan. 2019;39(6):875-84. 26. Kundap UP, Choo BKM, Kumari Y, Ahmed N, Othman I Bin, Shaikh MF. Embelin protects against acute pentylenetetrazole-induced seizures and positively modulates cognitive function in adult zebrafish. Front Pharmacol. 2019;10(October):I-18.

27. Choo BKM, Kundap UP, Johan Arief MF bin, Kumari Y, Yap JL, Wong CP, et al. Effect of newer anti-epileptic drugs (AEDs) on the cognitive status in pentylenetetrazol induced seizures in a zebrafish model. Prog Neuro-Psychopharmacology Biol Psychiatry. 2019;92:483-93.

28. Brenet A, Hassan-Abdi R, Somkhit J, Yanicostas C, Soussi-Yanicostas N. Defective excitatory/inhibitory synaptic balance and increased neuron apoptosis in a zebrafish model of Dravet syndrome. bioRxiv. 2019;I-I3.

29. Kundap UP, Kumari Y, Othman I, Shaikh MF. Zebrafish as a Model for EpilepsyInduced Cognitive Dysfunction: A Pharmacological, Biochemical and Behavioral Approach. Front Pharmacol. 2017 Aug 3;8(AUG):515.

30. Gaind N. US grants for zebrafish studies on the rise. Nature. 2016 Aug 9;

31. Howe K, Clark MD, Torroja CF, Torrance J, Berthelot C, Muffato M, et al. The zebrafish reference genome sequence and its relationship to the human genome. Nature. 2013 Apr 25;496(7446):498-503.

32. Raftery TD, Volz DC. Abamectin induces rapid and reversible hypoactivity within early zebrafish embryos. Neurotoxicol Teratol. 2015 May i;49:10-8.

33. Almeida DV, Vaz B, Azevedo Figueiredo M, Junior ASV, Marins LF. Fluorescent transgenic zebrafish as a biosensor for growth-related effects of methyl parathion. Aquat Toxicol. 2014 Jul i;152:147-51.

34. Cho SJ, Byun D, Nam TS, Choi SY, Lee BG, Kim MK, et al. Zebrafish as an animal model in epilepsy studies with multichannel EEG recordings. Sci Rep. 2017 Dec I;7(I):I-Io.

35. Grone BP, Baraban SC. Animal models in epilepsy research: Legacies and new directions. Vol. 18, Nature Neuroscience. Nature Publishing Group; 2015. p. 339-43.

36. Sassen A, Köster RW. Advances in Genomics and Genetics Dovepress A molecular toolbox for genetic manipulation of zebrafish. Adv Genomics Genet. 2015;5-15I.

37. Santana S, Rico EP, Burgos JS. Can zebrafish be used as animal model to study Alzheimer's disease? Vol. I, American Journal of Neurodegenerative Diseases. E-Century Publishing Corporation; 2012. p. 32-48.

38. Baraban SC, Taylor MR, Castro PA, Baier H. Pentylenetetrazole induced changes in zebrafish behavior, neural activity and c-fos expression. Neuroscience. 2005 Jan I;13I(3):75968.

39. Mussulini BHM, Leite CE, Zenki KC, Moro L, Baggio S, Rico EP, et al. Seizures Induced by Pentylenetetrazole in the Adult Zebrafish: A Detailed Behavioral Characterization. Callaerts P, editor. PLoS One. 2013 Jan 21;8(I):e54515.

40. Shams S, Rihel J, Ortiz JG, Gerlai R. The zebrafish as a promising tool for modeling human brain disorders: A review based upon an IBNS Symposium. In: Neuroscience and Biobehavioral Reviews. Elsevier Ltd; 2018. p. 176-90.

4I. Afrikanova T, Serruys ASK, Buenafe OEM, Clinckers R, Smolders I, de Witte PAM, et al. Validation of the Zebrafish Pentylenetetrazol Seizure Model: Locomotor versus Electrographic Responses to Antiepileptic Drugs. PLoS One. 2013;8(I):I-9.

42. Ying C, Ying L, Yanxia L, Le W, Lili C. High mobility group box I antibody represses autophagy and alleviates hippocampus damage in pilocarpine-induced mouse epilepsy model. Acta Histochem. 2020 Feb i;122(2):151485.

43. Durairaj B, Manish R. Zebrafish: An in vivo model for the study of therapeutic targets of epilepsy. NeuroRegulation. 2019;6(4):190-6. 
44. Møller RS, Dahl HA, Helbig I. The contribution of next generation sequencing to epilepsy genetics. Expert Rev Mol Diagn. 2015 Dec 2;15(12):1531-8.

45. Myers CT, Stong N, Mountier EI, Helbig KL, Freytag S, Sullivan JE, et al. De Novo Mutations in $\mathrm{PPP}_{3} \mathrm{CA}$ Cause Severe Neurodevelopmental Disease with Seizures. Am J Hum Genet. 2017 Oct 5;10I(4):516-24.

46. Dunn P, Albury CL, Maksemous N, Benton MC, Sutherland HG, Smith RA, et al. Next generation sequencing methods for diagnosis of epilepsy syndromes. Vol. 9, Frontiers in Genetics. Frontiers Media S.A.; 2018.

47. Griffin A, Krasniak C, Baraban SC. Advancing epilepsy treatment through personalized genetic zebrafish models. In: Progress in Brain Research. Elsevier B.V.; 2016. p. $195-207$.

48. Zhang C, Li C, Chen S, Li Z, Jia X, Wang K, et al. Berberine protects against 6OHDA-induced neurotoxicity in $\mathrm{PC}_{12}$ cells and zebrafish through hormetic mechanisms involving $\mathrm{PI}_{3} \mathrm{~K} / \mathrm{AKT} / \mathrm{Bcl}_{2}$ and $\mathrm{Nrf}_{2} / \mathrm{HO}$-I pathways. Redox Biol. $2017 \mathrm{Apr}$ i; II:I-II.

49. Dauer W, Przedborski S. Parkinson's disease: Mechanisms and models. Vol. 39, Neuron. Cell Press; 2003. p. 889-909.

5o. Shubhra Chakrabarti S, Bir A, Poddar J, Sinha M, Ganguly A, Chakrabarti S. Ceramide and Sphingosine-r-Phosphate in Cell Death Pathways: Relevance to the Pathogenesis of Alzheimer's Disease. Curr Alzheimer Res. 2016;13:1232-1248.

51. Buenafe OE, Orellana-Paucar A, Maes J, Huang H, Ying X, De Borggraeve W, et al. Tanshinone IIA exhibits anticonvulsant activity in zebrafish and mouse seizure models. ACS Chem Neurosci. 2013 Nov 20;4(II):1479-87.

52. Samarut É, Swaminathan A, Riché R, Liao M, Hassan-Abdi R, Renault S, et al. $\gamma$ Aminobutyric acid receptor alpha I subunit loss of function causes genetic generalized epilepsy by impairing inhibitory network neurodevelopment. Epilepsia. 2018 Nov I;59(II):206i-74.

53. Swaminathan A, Hassan-Abdi R, Renault S, Siekierska A, Riché R, Liao M, et al. Non-canonical mTOR-Independent Role of DEPDC 5 in Regulating GABAergic Network Development. Curr Biol. 2018 Jun 18;28(12):1924-1937.e5.

54. Zhang Y, Kecskés A, Copmans D, Langlois M, Crawford AD, Ceulemans B, et al. Pharmacological characterization of an antisense knockdown zebrafish model of Dravet syndrome: Inhibition of epileptic seizures by the serotonin agonist fenfluramine. PLoS One. 2015 May 12;10(5).

55. Baraban SC, Dinday MT, Hortopan GA. Drug screening in Scnia zebrafish mutant identifies clemizole as a potential Dravet syndrome treatment. Nat Commun. 2013;4.

56. Rosch RE, Hunter PR, Baldeweg T, Friston KJ, Meyer MP. Calcium imaging and dynamic causal modelling reveal brain-wide changes in effective connectivity and synaptic dynamics during epileptic seizures. PLoS Comput Biol. 2018 Aug I;14(8).

57. Turrini L, Fornetto C, Marchetto G, Müllenbroich MC, Tiso N, Vettori A, et al. Optical mapping of neuronal activity during seizures in zebrafish. Sci Rep. 2017 Dec I;7(I).

58. Vezzani A, Granata T. Brain inflammation in epilepsy: Experimental and clinical evidence. Vol. 46, Epilepsia. John Wiley \& Sons, Ltd; 2005. p. 1724-43.

59. Vezzani A, French J, Bartfai T, Baram TZ. The role of inflammation in epilepsy. Vol. 7, Nature Reviews Neurology. Nature Publishing Group; 20II. p. 3I-40.

6o. Vezzani A, Aronica E, Mazarati A, Pittman QJ. Epilepsy and brain inflammation. Vol. 244, Experimental Neurology. Academic Press; 2013. p. II-2I.

6I. Maroso M, Balosso S, Ravizza T, Liu J, Aronica E, Iyer AM, et al. Toll-like receptor 4 and high-mobility group box-I are involved in ictogenesis and can be targeted to reduce seizures. Nat Med. 2010 Apr 28;16(4):413-9. 
62. $\mathrm{Qu} \mathrm{Z,} \mathrm{Jia} \mathrm{L,} \mathrm{Xie} \mathrm{T,} \mathrm{Zhen} \mathrm{J,} \mathrm{Si} \mathrm{P,} \mathrm{Cui} \mathrm{Z,} \mathrm{et} \mathrm{al.} \mathrm{(-)-Epigallocatechin-3-gallate} \mathrm{protects}$ against lithium-pilocarpine-induced epilepsy by inhibiting the toll-like receptor 4 (TLR4)/ nuclear factor-kB (NF-kB) signaling pathway. Med Sci Monit. 2019;25:1749-58.

63. Liu AH, Wu YT, Wang YP. MicroRNA-129-5p inhibits the development of autoimmune encephalomyelitis-related epilepsy by targeting HMGBI through the TLR4/NF-kB signaling pathway. Brain Res Bull. 2017 Jun 1;132:139-49.

64. Shi Y, Zhang L, Teng J, Miao W. HMGB mediates microglia activation via the TLR4/NF- $\kappa B$ pathway in coriaria lactone induced epilepsy. Mol Med Rep. 2018 Apr I;17(4):5125-31.

65. Vezzani A, Granata T. Brain inflammation in epilepsy: Experimental and clinical evidence. Vol. 46, Epilepsia. Epilepsia; 2005. p. 1724-43.

66. Rijkers K, Majoie HJ, Hoogland G, Kenis G, De Baets M, Vles JS. The role of interleukin-I in seizures and epilepsy: A critical review. Vol. 216, Experimental Neurology. Exp Neurol; 2009. p. 258-71.

67. Gall CM. Seizure-induced changes in neurotrophin expression: Implications for epilepsy. Exp Neurol. 1993;124(I):150-66.

68. Zhu X, Han X, Blendy JA, Porter BE. Decreased CREB levels suppress epilepsy. Neurobiol Dis. 2012 Jan I;45(I):253-63.

69. Kandel ER. The molecular biology of memory: CAMP, PKA, CRE, CREB-I, CREB2, and CPEB. Vol. 5, Molecular Brain. BioMed Central; 20I2. p. I4.

7o. Noe F, Vaghi V, Balducci C, Fitzsimons H, Bland R, Zardoni D, et al. Anticonvulsant effects and behavioural outcomes of rAAV serotype I vector-mediated neuropeptide y overexpression in rat hippocampus. Gene Ther. 2010 May II;17(5):643-52.

71. Gøtzsche CR, Woldbye DPD. The role of NPY in learning and memory. Vol. 55, Neuropeptides. Churchill Livingstone; 2016. p. 79-89.

72. Luo J, Min S, Wei K, Li P, Dong J, Liu YF. Propofol protects against impairment of learning-memory and imbalance of hippocampal Glu/GABA induced by electroconvulsive shock in depressed rats. J Anesth. 20II Jul 19;25(5):657-65.

73. Kaila K, Ruusuvuori E, Seja P, Voipio J, Puskarjov M. GABA actions and ionic plasticity in epilepsy. Vol. 26, Current Opinion in Neurobiology. Curr Opin Neurobiol; 2014. p. 34-4I.

74. Chapman AG. Glutamate and epilepsy. In: Journal of Nutrition. American Institute of Nutrition; 2000.

75. Miller HP, Levey AI, Rothstein JD, Tzingounis A V., Conn PJ. Alterations in glutamate transporter protein levels in kindling-induced epilepsy. J Neurochem. 1997;68(4):1564-70.

76. Holmes GL. Seizure-induced neuronal injury: Animal data. Neurology. 2002 Nov 12;59(9 SUPPL.).

77. Izquierdo I, Medina JH. Memory formation: The sequence of biochemical events in the hippocampus and its connection to activity in other brain structures. Neurobiol Learn Mem. 1997 Nov 1;68(3):285-316.

78. ATZORI M, KANOLD P, PINEDA JC, FLORES-HERNANDEZ J. DopamineAcetylcholine Interactions in the Modulation of Glutamate Release. Ann N Y Acad Sci. 2003 Nov i;1003(I):346-8.

79. Yang JW, Czech T, Felizardo M, Baumgartner C, Lubec G. Aberrant expression of cytoskeleton proteins in hippocampus from patients with mesial temporal lobe epilepsy. Amino Acids. 2006 Jun 4;30(4):477-93.

8o. Schoonjans AS, Lagae L, Ceulemans B. Low-dose fenfluramine in the treatment of neurologic disorders: Experience in Dravet syndrome. Vol. 8, Therapeutic Advances in Neurological Disorders. SAGE Publications; 2015. p. 328-38. 
8I. Baraban SC, Dinday MT, Hortopan GA. Drug screening in Scnia zebrafish mutant identifies clemizole as a potential Dravet syndrome treatment. Nat Commun. 2013;4:2410.

82. Eimon PM, Ghannad-Rezaie M, De Rienzo G, Allalou A, Wu Y, Gao M, et al. Brain activity patterns in high-throughput electrophysiology screen predict both drug efficacies and side effects. Nat Commun. 2018 Dec I;9(I).

83. Zhang Y, Kecskés A, Copmans D, Langlois M, Crawford AD, Ceulemans B, et al. Pharmacological Characterization of an Antisense Knockdown Zebrafish Model of Dravet Syndrome: Inhibition of Epileptic Seizures by the Serotonin Agonist Fenfluramine. Herault Y, editor. PLoS One. 2015 May 12;10(5):eo125898.

84. El-Brolosy MA, Stainier DYR. Genetic compensation: A phenomenon in search of mechanisms. Vol. 13, PLoS Genetics. Public Library of Science; 2017.

85. Lawson ND. Reverse Genetics in Zebrafish: Mutants, Morphants, and Moving Forward. Vol. 26, Trends in Cell Biology. Elsevier Ltd; 2016. p. 77-9.

86. de Bruijn E, Cuppen E, Feitsma H. Highly Efficient ENU Mutagenesis in Zebrafish. Methods Mol Biol. 2009;546:3-12.

87. Griffin A, Hamling KR, Knupp K, Hong SG, Lee LP, Baraban SC. Clemizole and modulators of serotonin signalling suppress seizures in Dravet syndrome. Brain. 2017 Mar I;140(3):669-83. 